\title{
How Do Chinese International Students View Seeking Mental Health Services?
}

\author{
Huan Chen \\ University of North Texas, USA \\ Usenime Akpanudo \\ Erin Hasler \\ Harding University, USA
}

\begin{abstract}
This study explored how Chinese international students view seeking mental health services. One hundred and ten Chinese international students responded to the Attitude Toward Seeking Professional Psychological Help Scale-Short Form (ATSPPH-SF) and a demographic questionnaire. Results of our data analysis revealed no significant main effects of the demographic factors (gender, length of stay in the United States, and awareness of on-campus counseling services) on attitudes toward seeking mental health services. However, awareness of on-campus counseling services was found to be a mediating factor in the relationship between gender and students' mental health help-seeking attitudes. Based on the findings, we make recommendations on how student affairs professionals can better serve the mental health needs of Chinese and other international students.
\end{abstract}

Keywords: acculturation, Chinese international students, gender, help-seeking behaviors, mental health

\section{INTRODUCTION}

The number of Chinese students choosing to pursue higher education in the United States is at an all-time high. According to the Institute of International Education (IIE, 2017), between 2015 and 2017, the number of students of Chinese origin enrolled in 
tertiary institutions across the United States rose from 328,547 to 350,775 . In many ways, China has become the top contributor of international students to colleges and universities in the United States (Kataria, 2018). It is, therefore, more important than ever for all stakeholders involved in the education of Chinese international students to have a clear understanding of the issues that affect this group of students in light of the unique academic, social, and emotional challenges they face. While nativeborn students may only have to deal with the traditional challenges of settling into a college environment (keeping up with academic demands, establishing relationships, managing personal finances, etc.), international students typically have the additional burden of adjusting to a new cultural context within which the school is situated. These additional cultural challenges often manifest in the form of language barriers, identity conflicts, and unfamiliar cultural norms (Jibreel, 2015), which can take a heavy toll on mental health.

In recent times, these cultural challenges have been exacerbated by a sociopolitical context that is increasingly unwelcoming of non-indigenes. According to Kataria (2018), proposed restrictions that affect several visa categories used by international students will make it even more difficult for future students to obtain visas. In light of these looming policy changes, some international students have expressed feeling anxious, discouraged, and even nervous about their stay in the country (Baer, 2017; Kataria, 2018). Others have become worried about the narrowing opportunities for internships and postgraduation employment (Baer, 2017; O'Malley, 2018). While international students may be vividly aware of the unique challenges they face, many are oblivious of the emotional and mental toll associated with these challenges. Furthermore, even fewer of them will assign priority to attending to the stress that comes from coping with these challenges. Unfortunately, this same disconnect in reasoning about mental health among international students extends to international student affairs units where current practices at many schools do not prioritize addressing the mental health concerns of international students $(\mathrm{Qu}$, 2018). In the end, a large number of international students in the United States will continue to operate under conditions of high stress, doing so in the shadows because they are unaware they need help, are unwilling to seek it, or do not know how to get it.

We believe this situation raises important questions that should be of concern to all educators who work with international students. Such questions include: What attitudes do international students display toward seeking psychological help while in the United States? What strategies can higher education practitioners adopt to support this group of students? In this article, we aim to explore and make meaningful contributions toward addressing these questions as they apply to Chinese international students.

\section{LITERATURE REVIEW}

Awareness of the challenges faced by international students and the resulting psychological toll of these challenges is not entirely new (e.g., Akanwa, 2015; Alakaam et al., 2015; Chalungsooth \& Schneller, 2011; Leong, 2015; Yang et al., 2015). Traditionally, colleges and universities in the United States have provided a 
range of interventions to help international students cope with the pressures of learning a new language, managing their financial commitments, and meeting academic requirements. The list of such accommodations includes language classes, scholarships, and academic support counseling. Unfortunately, while many colleges and universities have interventions in place for students who need academic support, typically a narrower range of interventions exists for students who have difficulty adjusting to campus life and feeling safe on campus (Baer, 2017). For instance, Baer noted the following five top actions institutions across the country have taken to address the concerns of Chinese international students who struggle to make adjustments: (a) encouraging them to reach out to faculty, staff, and counselors; (b) working with them to develop networking opportunities on campus; (c) holding seminars about academic integrity standards; (d) providing resources on cultural differences between China and the United States; and (e) hiring Chinese-speaking international student services staff/counselors.

University administrators are actively seeking solutions to assist their Chinese international students in making the best of their college experiences. For instance, the consideration of hiring Chinese-speaking counselors, though given lower priority on the list, reflects a desire to engage the services of professionals who are knowledgeable of students' needs based on their countries of origin (Tidwell \& Hanassab, 2007). Unfortunately, the ability to hire such a diverse set of counseling professionals may lie outside the budgetary reach of many institutions that enroll international students. To assist in other ways, Olivas and Li (2006) suggested that institutions promote the mental health of their international students, which can be done by helping student affairs professionals become better informed about the home culture of the students they serve. As a starting point, student affairs professionals can prepare to meet the needs of international students by first understanding how the students themselves perceive of such needs (Tidwell \& Hanassab, 2007), as well as the factors that might help shape these perceptions.

\section{The Impact of Gender}

Assuming gender plays an important role in shaping attitudes toward helpseeking (Tedeschi \& Willis, 1993), studies examining the effects of gender on helpseeking behaviors among Asian populations have produced mixed results. Even though gender is not a significant predictor of Chinese students' attitudes toward seeking psychological help (e.g., Tang et al., 2012; Zhang \& Dixon, 2003), some researchers have argued that gender has a significant effect on students' help-seeking attitudes in general (Leong \& Zachar, 1999), particularly for Chinese, Asian, and Asian-American students (e.g., Chang, 2008; Galligan, 2016; Mojaverian et al., 2013; Sheu \& Sedlacek, 2004; Tedeschi \& Willis, 1993; Yoon \& Jepsen, 2008). In studies where gender was identified as an important factor in help-seeking attitudes, the findings consistently revealed women as reporting more favorable attitudes than men.

Although the case can be made that female Chinese students have more favorable attitudes toward seeking psychological help than their male counterparts, these attitudes do not always translate into seeking mental health services. According to Chang (2008), Chinese students, regardless of gender, prefer to seek informal help 
from family members and friends rather than contacting mental health professionals. Thus, even though Chinese men and women may differ in their attitudes toward mental health, they display similar behaviors in not pursuing professional help. Furthermore, if professional help is sought, Chinese students are more likely to seek help for academic and career concerns instead of for interpersonal and emotional concerns (Chang, 2008; Sheu \& Sedlacek, 2004). This complexity in actual behaviors versus self-reported attitudes means that self-reported attitudes are just a starting point to a comprehensive understanding of the impact of gender on mental health helpseeking behaviors of Chinese international students.

\section{The Impact of Acculturation and Length of Stay}

Chinese international students' comfort level in the cultural context of the United States may also impact their help-seeking behaviors and attitudes. Culture impacts behavior in profound ways. According to Saint Arnault (2009):

The cultural model "tells" the person to attend to certain aspects of his or her experience, what to ignore, what things mean, and what should be done about them. Understanding how a given cultural model might direct attention is a starting point for making predictions about how the sensations within the body, emotions, and social situations will be perceived and therefore how health is maintained or distress is experienced. (p. 263)

Cultural values are therefore critical to understand how people frame mental health issues and how they interpret actions or inactions with regards to seeking help. Cultural practices in China and the United States appear to be at opposite ends of a cultural continuum. Samovar and Porter (1991) described this phenomenon as the two cultures having a maximum level of cultural distance. It is therefore important to consider how ethnic identity and acculturation may define Chinese international students' attitudes toward seeking mental health services while in the United States (Yan \& Berliner, 2011).

According to Lu et al. (2014), Chinese-speaking international students associate seeking mental health services with shame and a loss of respect if others were to find out that they were receiving such services. In Chinese culture, this feeling of shame is often referred to as "losing face" ( $\mathrm{Lu}$ et al., 2014). Because individuals are concerned about their public image and are conscious of how others view them, they inhibit feelings of distress to avoid losing face (Chen \& Mak, 2008). This fear of embarrassment (among those with strong Chinese cultural identity) decreases their likelihood of having positive attitudes and intentions toward seeking help (Chen et al., 2014; Yakunina \& Weigold, 2011), using mental health services (Li et al., 2016), initiating discussions about personal problems (Chen \& Mak, 2008), or expressing personal emotions to mental health professionals (Mak \& Chen, 2006).

Saint Arnault (2009) also noted that this shame can extend beyond the individual seeking mental health services such that it is interpreted as an inability of the family to fulfill its social support role, casting shame on the entire family. Given the weighty consequences surrounding the issue of mental health in Chinese culture, the expectation would be that individuals who strongly identify with traditional Chinese 
culture are less willing to seek mental health services than those who do not strongly subscribe to the norms of the culture or those who have become acculturated to other cultures. Mojoverian et al. (2013) described a similar aversion to being stigmatized among Japanese participants that were significantly different from those of United States participants.

If traditional Asian and Chinese cultural values impose negative constraints on attitudes toward seeking professional mental health services, does exposure to other cultures have any effect on such attitudes? Zhang and Dixon (2003), as well as Li et al. (2016), found that the higher the level of acculturation, the more positive the attitudes toward seeking mental health services. This positive effect of acculturation to western culture is also true with regards to the views about mental health professionals in general among Chinese international students (Sheu \& Fukuyama, 2007).

Although the process of acculturation is multifaceted and can occur through a variety of stages, the length of stay in a cultural context is a reliable predictor of acculturation to cultures that are significantly different from a person's home culture (Melius \& Cannonier, 2016; Zheng, 2016). Merta et al. (1992) found the length of stay in the United States is directly related to Asian male international students' likelihood to seek out counseling. It should be noted, however, that the positive outcomes of the length of stay can come with some negative side effects as well. For instance, the length of time in the United States and acculturative stress are also important predictors of depression among Chinese college students (Wei et al., 2007). Furthermore, the length of stay in the United States may not always have a positive effect on Chinese international students' attitudes and views of mental health helpseeking (Huo, 2014) in less culturally distant locations. The length of stay showed no significant effect on the level of acculturative stress for Chinese students in Singapore (Nasirudeen et al., 2014). The need for investigations of this phenomenon extends beyond unidimensional assumptions of the connections between the length of stay and help-seeking behaviors.

\section{The Impact of Awareness of On-Campus Services}

Several key differences exist between international students and their American counterparts in regards to their knowledge of and the likelihood of using mental health services. International students at American universities tend to have significantly lower awareness and knowledge of the counseling services available on campus than domestic students (Hyun et al., 2007; Nina 2009). Also, international students have reported significantly lower rates of using counseling services than domestic students (Hyun et al., 2007; Sheu \& Sedlacek, 2004). International students, particularly Asian-American students (Sheu \& Sedlacek, 2004), are less likely than domestic students to engage in healthy forms of emotional copings, such as seeking emotional support, which would indicate knowledge of mental health services, and are more likely to engage in unhealthy forms of coping, such as avoidance (Mortenson, 2006). Beyond these, there is limited literature on how awareness of services may influence the help-seeking attitudes or behaviors of international students. The consideration of how the awareness of on-campus services may be related to the help-seeking attitudes 
of international students, or how it might interact with other factors to influence their attitudes, is particularly interesting.

The range of challenges faced by international students in the United States as they struggle to make academic and cultural adjustments is well documented in the extant literature. Unfortunately, in the past, merely identifying these challenges has not automatically translated into actionable practices. One of the reasons for this disconnect is the gap in understanding of the attitudes underlying international students' adjustment decisions, as well as an incomplete understanding of the factors that influence such attitudes. This is especially true as the social environment in the United States continually changes, presenting new challenges for international students. This phenomenon requires ongoing investigation.

In this study, the aim is to add to the existing body of knowledge and increase understanding of this phenomenon by exploring how demographic characteristics such as gender, the length of stay in the United States, and the awareness of oncampus counseling services may affect the help-seeking attitudes of a specific group of international students. This study is an investigation of how Chinese international students view seeking mental health services as they adjust to life in the United States. Ultimately, the findings will raise awareness about the mental health challenges of international students and inform culturally competent counseling practices that can help these students overcome such challenges. In this study, the term "international student" is used in reference to those students who, though not citizens of the United States, possess valid nonimmigrant visas that allow them to enroll for academic credit at an institution of higher education in the United States.

\section{Research Questions}

To address the purpose of this study, the following research questions were developed:

RQ1: To what extent do gender and length of stay in the United States influence the attitudes toward seeking mental health services among Chinese students?

RQ2: To what extent do gender and awareness of on-campus counseling services influence the attitudes toward seeking mental health services among Chinese students?

\section{METHOD}

\section{Sample}

A convenience sample of 113 Chinese international students enrolled at two universities in the southeastern United States was obtained for this nonexperimental study. Data were obtained using a survey that allowed the subjects to complete the items either online or in person. Of the 113 responses submitted, three were incomplete and were therefore excluded, resulting in a total of 110 valid responses for data analysis. A majority of the sample (93\%) was drawn from one of the two 
universities while only $7 \%$ of the responses came from the second university. The demographic characteristics of respondents are presented in Table 1.

Table 1: Demographic Characteristics of Respondents

\begin{tabular}{|c|c|c|}
\hline Characteristic & $\%$ Male $(n=57)$ & $\%$ Female $(n=53)$ \\
\hline \multicolumn{3}{|l|}{ Marital Status } \\
\hline Single & 91.1 & 88.7 \\
\hline Married & 8.9 & 11.3 \\
\hline \multicolumn{3}{|l|}{ Age } \\
\hline$<20$ & 28.1 & 22.6 \\
\hline $21-25$ & 66.7 & 75.5 \\
\hline $36-30$ & 5.3 & 1.9 \\
\hline \multicolumn{3}{|l|}{ Major } \\
\hline Business & 77.2 & 71.7 \\
\hline STEM & 10.5 & 1.9 \\
\hline Arts/Humanities/Social Sciences & 3.5 & 13.2 \\
\hline Education & 3.5 & 11.3 \\
\hline Unspecified & 5.3 & 1.9 \\
\hline \multicolumn{3}{|l|}{ GPA } \\
\hline $3.00+$ & 19.0 & 23.6 \\
\hline$<2.99$ & 6.3 & 7.2 \\
\hline N/A & 26.4 & 17.2 \\
\hline \multicolumn{3}{|l|}{ Religion } \\
\hline Atheism & 41.8 & 40.0 \\
\hline Christianity & 2.7 & 2.7 \\
\hline Buddhism & 7.2 & 5.5 \\
\hline \multicolumn{3}{|l|}{ Length of Stay } \\
\hline$<1 \mathrm{yr}$ & 20.0 & 11.8 \\
\hline $1-2 \mathrm{yr}$ & 25.5 & 24.5 \\
\hline $3+\mathrm{yr}$ & 5.4 & 9.1 \\
\hline \multicolumn{3}{|l|}{ Previous knowledge of counseling } \\
\hline No & 20.0 & 13.6 \\
\hline Yes & 31.8 & 32.7 \\
\hline \multicolumn{3}{|l|}{ Previous experience in counseling } \\
\hline No & 50.9 & 38.1 \\
\hline Yes & 1.8 & 7.2 \\
\hline \multicolumn{3}{|l|}{ Awareness of counseling center } \\
\hline No & 22.7 & 19.0 \\
\hline Yes & 23.6 & 14.5 \\
\hline \multicolumn{3}{|l|}{ Openness to receive counseling } \\
\hline No & 14.5 & 10.9 \\
\hline Yes & 37.2 & 34.5 \\
\hline
\end{tabular}




\section{Instrumentation}

Two instruments were used in this study: the Attitude Toward Seeking Professional Psychological Help Scale-Short Form (ATSPPH-SF) developed by Fischer and Farina (1995) and a demographic form developed by the researchers. The ATSPPH-SF is a widely used instrument for assessing attitudes toward seeking mental health treatment (Elhai et al., 2008). The ATSPPH-SF comprises 10 items on a 4-point Likert scale $(0=$ disagree, $1=$ partly disagree, $2=$ partly agree, $3=$ agree $)$ of which five are reverse scored (Picco et al., 2016). Scores on the scale range from 0 to 30 , with higher scores indicating a more favorable attitude toward seeking mental health services (Elhai et al., 2008). According to Fischer and Farina (1995), responses obtained from the short form of the scale are highly consistent $(r=.87)$ with those obtained from the original form of the scale (Attitude Toward Seeking Professional Psychological Help Scale-ATSPPHS) developed by Fischer and Turner (1970). Internal consistency reliability for the ATSPPH-SF is reasonable $([\alpha=.77]$, Elhai et al., 2008; [.82 to .84], Fischer \& Farina, 1995), although interitem correlations have been shown to be generally lower ([0.3 to 0.5], Elhai et al., 2008). The demographic form comprised 12 items that measured participants' gender, age, marital status, major, grade point average (GPA), religion, length of stay in the United States, previous knowledge of counseling, previous experience in counseling, and openness to receive counseling in the future.

\section{Procedure}

Respondents who volunteered to take the survey in this study were contacted through their course professor and personal communication. Students who were in the two university classes were given a paper-form of the survey, and the remaining participants were given an electronic form of the survey via Google forms. Before the administration of the surveys, approval was sought by the Institutional Review Board (IRB) for the research project. The participants who were given the paper form of the survey were provided an explanation of the nature of the study in-person in Mandarin and were asked to read through and sign the informed consent form before taking the survey. The participants who completed the electronic form were emailed a link to the Google form, which included instructions, informed consent, the demographic form, and ATSPPH-SF. The term "counseling," as well as informed consent and ATSPPH-SF, were presented in English and their Mandarin translation.

\section{RESULTS}

\section{Research Question 1}

To test the null hypothesis associated with the first research question in this study, a $3 \times 2$ factorial Analysis of Variance (ANOVA) was conducted at the $\alpha$ level of .05. Before conducting an ANOVA, data were examined to ensure that the assumptions for the test were met. Histograms, as well as Kolmogorov-Smirnov (KS) statistics, were examined for each group. Results for the KS tests revealed no 
significant deviation from a normal distribution for male students staying up to 1 year, $D(21)=0.184, p>.05 ; 1-2$ years, $D(29)=0.116, p>.05$; and over 3 years, $D(7)=$ $0.222, p>.05$. KS test results also indicated no significant deviation from a normal distribution for female students staying up to 1 year, $D(13)=0.148, p>.05 ; 1-2$ years, $D(28)=0.125, p>.05$; and more than 3 years, $D(12)=0.195, p>.05$. Similarly, Levene's test, $F(5,104)=1.50, p=.200$, revealed that the assumption of homogeneity of variances was met. Table 2 provides a summary of descriptive statistics of ATSPPH-SF scores for Chinese male and female students' length of stay in the United States.

Table 2: Gender and Length of Stay on Attitude Toward Seeking Mental Health of Chinese International Students

\begin{tabular}{lcccccccc}
\hline \multirow{2}{*}{$\begin{array}{l}\text { Length } \\
\text { of stay }\end{array}$} & \multicolumn{3}{c}{ Male } & \multicolumn{3}{c}{ Female } & \multicolumn{2}{c}{ Total } \\
\cline { 2 - 9 } & $n$ & $M$ & $S D$ & $n$ & $M$ & $S D$ & $M$ & $S D$ \\
\hline$<1 \mathrm{yr}$ & 21 & 15.90 & 4.60 & 13 & 17.31 & 2.69 & 16.44 & 3.99 \\
$1-2 \mathrm{yr}$ & 29 & 16.72 & 4.96 & 28 & 17.79 & 4.87 & 17.25 & 4.90 \\
$3+\mathrm{yr}$ & 7 & 16.86 & 2.27 & 12 & 19.17 & 2.82 & 18.32 & 2.81 \\
Total & 57 & 16.44 & 4.54 & 53 & 19.98 & 4.02 & 17.18 & 4.34 \\
\hline
\end{tabular}

The interaction between gender and the length of stay in the United States was not statistically significant for Chinese university students' attitudes toward seeking professional mental health, $F(2,104)=.14, p>.05, \eta^{2}=.003$. Although the results show a general pattern of more positive attitudes toward seeking mental health as the length of stay in the United States increased for both male and female students, this interaction effect was not statistically significant. Similarly, when the main effects of gender, $F(1,104)=2.88, p>.05, \eta^{2}=.027$, and the length of stay, $F(2,104)=0.61$, $p>.05, \eta^{2}=.012$, were examined separately, neither revealed a statistically significant effect on attitude toward seeking help (Figure 1). 


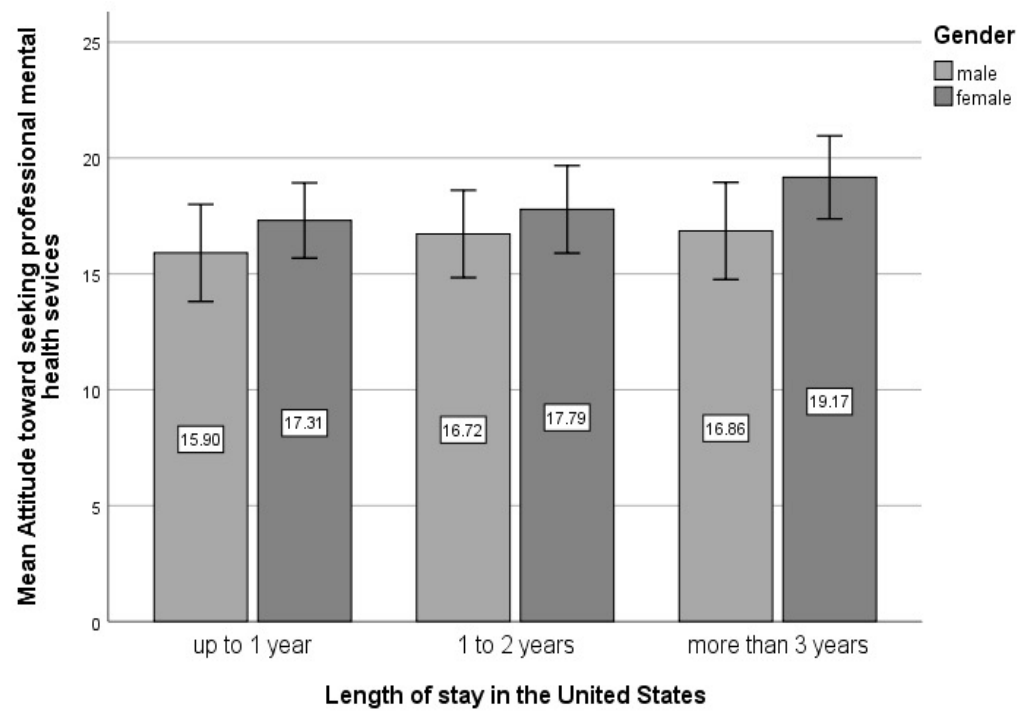

Error bars: $95 \% \mathrm{Cl}$

\section{Figure 1: Effect of Gender and Length of Stay in the United States on Attitude Toward Seeking Professional Mental Health Services}

These results suggest that there is little evidence that gender and length of stay in the United States in combination, or individually, exert a significant influence on the attitudes of Chinese students toward seeking mental health services.

\section{Research Question 2}

The participants who responded to the paper form of the instruments $(n=88)$ were asked to indicate their awareness of the counseling center on campus. To test the null hypotheses associated with the interaction of gender and awareness of oncampus health services, as well as their main effects, a $2 \times 2$ factorial ANOVA was conducted to address the second research question at the $\alpha$ level of .05. Histograms, as well as KS statistics, were examined for each group, and the assumption of normality had been achieved. All groups appeared normal and results for the KS tests revealed no significant deviation from a normal distribution for male students who did not know about the counseling center, $D(24)=0.153, p>.05$; male students who knew about the counseling center, $D(26)=0.119, p>.05$; and female students who did not know about the counseling center, $D(21)=0.131, p>.05$. However, female students who know about the counseling center violated the assumption of normality, $D(16)=0.261, p<.05$. Despite the violation, ANOVA is considered appropriate to mild violations of the assumption of normality. As for the homogeneity of variances, Levene's test, $F(3,83)=0.783, p=.507$, revealed no statistically significant violation 
of the assumption. Table 3 displays a summary of descriptive statistics of ATSPPHSF scores for Chinese male and female students' awareness of on-campus counseling center.

Table 3: Gender and Awareness of Counseling Center

\begin{tabular}{lcccccccc}
\hline Awareness & \multicolumn{3}{c}{ Male } & \multicolumn{3}{c}{ Female } & \multicolumn{2}{c}{ Total } \\
\cline { 2 - 9 } & $n$ & $M$ & $S D$ & $N$ & $M$ & $S D$ & $M$ & $S D$ \\
\hline No & 24 & 15.08 & 4.88 & 21 & 18.19 & 4.12 & 16.53 & 4.76 \\
Yes & 26 & 17.81 & 3.87 & 16 & 16.06 & 4.23 & 17.14 & 4.05 \\
Total & 50 & 16.50 & 4.55 & 37 & 17.27 & 4.25 & 16.83 & 4.42 \\
\hline
\end{tabular}

The interaction between male and female students' attitude toward seeking professional mental health services and their awareness of a counseling center on campus was significant, $F(1,83)=6.714, p<.05, \eta^{2}=.075$. Neither the main effects for gender, $F(1,83)=0.529, p>.05, \eta^{2}=.006$, nor awareness of on-campus counseling center, $F(1,83)=0.101, p>.05, \eta^{2}=.001$, on attitude were significant (Figure 2). To further explore the significant interaction, an examination of the simple effects of gender on awareness of the campus counseling center revealed a significant difference by gender for students who were not aware of on-campus counseling services, $\mathrm{F}(1,83)=5.87, p=.018$, such that male students in this category had significantly lower attitudes toward mental health services than those of their female counterparts. This difference constitutes a medium effect size $d=.69$ (Cohen, 1988).

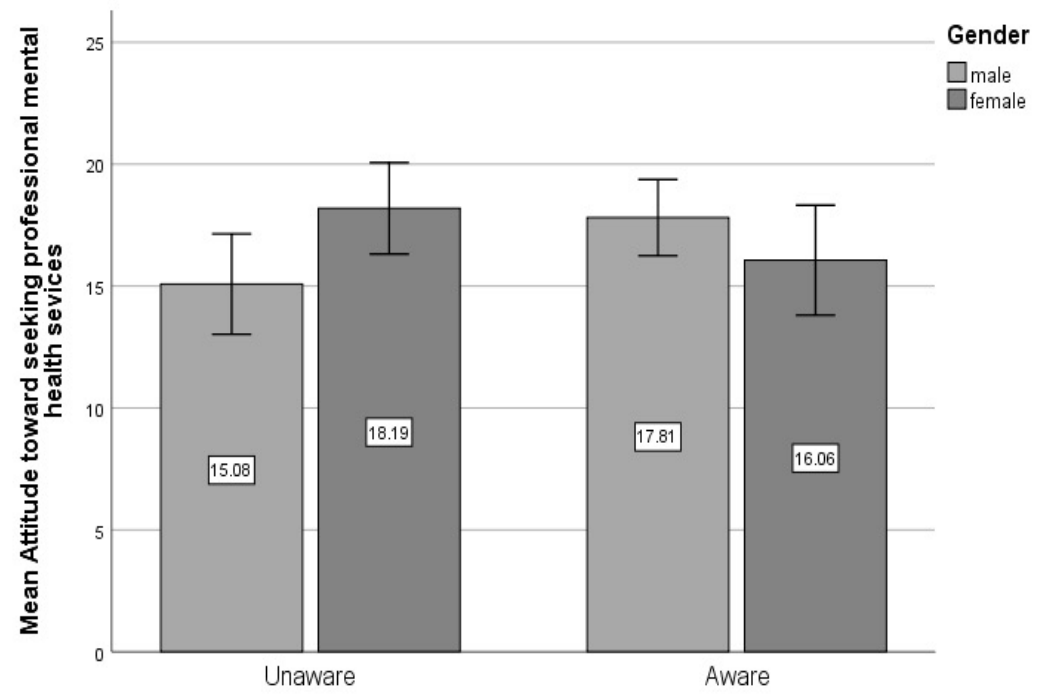

Awareness of Counseling Center

Error bars: $95 \% \mathrm{Cl}$

Figure 2: Gender and Awareness of Counseling Center on Attitude Toward Seeking Professional Mental Health Services 
These results indicate that for those Chinese students who are aware of oncampus counseling services, gender does not have a significant effect on their attitude toward seeking mental health services. However, among those who are unaware of the availability of on-campus counseling services, male students have attitudes that are significantly less positive toward seeking mental health services than do female students.

\section{DISCUSSION AND CONCLUSIONS}

The purpose of this study was to examine the effects of gender, length of stay in the United States, and awareness of on-campus counseling services on the attitudes toward seeking mental health services of Chinese international students. Overall, the findings of this study were mixed. The data analysis revealed that the effect of the length of stay on Chinese international students' attitudes toward mental health services was minimal at best, regardless of the student's gender. Male Chinese international students were no more likely than their female counterparts to seek mental health services. Similarly, Chinese students who had been in the United States for different time periods (ranging from under 1 year to 3 or more years) did not differ in their self-reported attitudes toward seeking mental health. However, when the influence of awareness of on-campus counseling services was considered as a moderating factor in the relationship between students' demographic characteristics and their mental health help-seeking attitudes, significant differences by gender were identified for students who were not aware of the availability of such facilities on campus. These findings revealed that male students who were unaware of such facilities had an appreciably lower attitude toward seeking mental health services than their female counterparts. The analysis did not reveal a comparable difference in attitude between male and female students who were aware of on-campus counseling services. Our finding in this regard is, however, not an assertion of the direction of the relationship between attitudes toward mental health and awareness of available mental health services, nor is it an indication of a causal relationship between the variables. For instance, it is entirely possible that male students with positive attitudes toward seeking mental health were also more likely to seek out and be aware of the mental health services available to them on campus. In all, our findings suggest the existence of an interesting relationship between attitudes toward mental health and awareness of available mental health services among Chinese international students that merits further investigation.

These findings are particularly relevant as they add to the literature regarding the influence that gender, cultural adjustment, and knowledge of on-campus opportunities to receive mental health services may have on mental health helpseeking among international students. The findings on gender mirror those of prior studies where gender was found to not affect attitudes toward seeking professional psychological help for Asian international students in general (Zhang \& Dixon, 2003) or Chinese international students in particular (Tang et al., 2012). These findings, however, stand in contrast to the extant literature suggesting that women in general (Fischer \& Farina, 1995; Fischer \& Turner, 1970; Leong \& Zachar, 1999; Nam et al., 2010; Pfohl, 2010; Sheu \& Sedlacek, 2004), and Asian or Chinese female students in 
particular (Chang, 2008; Kuo et al., 2006; Tedeschi \& Willis 1993; Yoon \& Jepsen, 2008) are more open to seeking professional psychological help than their male counterparts.

In relation to cultural adjustment/acculturation, the focus in the current study was on the length of stay as an indicator of cultural adjustment. Although the findings suggest that this may not be a significant influence on attitudes toward mental health help-seeking in this population, as was the case with gender, other researchers who studied acculturation directly have reported different findings. Zhang and Dixon (2003), as well as Wang (2013), found acculturation to western cultural norms to be positively associated with willingness to seek professional psychological help, while strong conformity to Asian cultural values was identified as a negative predictor of the willingness to seek help (Wang, 2013). The differences between this study's findings and the literature suggest a need for additional investigation into this phenomenon, particularly as this relates to different subpopulations of international students.

Prior work concerning how knowledge of the availability of services affects attitudes toward seeking psychological help in international student populations is limited. In a recent study of military service members and veterans, however, Mohatt et al. (2017) suggested that such knowledge can significantly improve attitudes. Similarly, Yousaf and Popat (2015) showed that providing information through priming significantly improves attitudes toward psychological help seeking in adult men, a population known to hold negative attitudes in this regard (Cheng et al., 2018; Leong \& Zachar, 1999, Nam et al., 2010). In the current study, the magnitude of the difference in attitude between male and female students who were not aware of counseling services implies that a lack of information about opportunities to seek help may further galvanize existing cultural biases toward help-seeking among male Chinese international students. Further research would provide additional information on the relative importance of this factor in influencing help-seeking attitudes and behavior.

Finally, it is worth noting that the average attitude scores in this study were relatively lower than those of other groups previously examined using the ATSPPHSShort Form, including the visually impaired (Heaslip, 2016), graduate counseling students (Pfohl, 2010), undergraduate students in Turkey (Topkaya, 2014), and college students in the United States (Cheng et al., 2018). The scores were similar to those recorded by Joseph (2010) for Canadians of African descent and higher than those reported for college students in mainland China (Fang et al., 2011). As Cheng et al. (2018) noted, low help-seeking is compounded by the high level of self-stigma and low mental health literacy among college students in general; therefore, this is even lower for Chinese international students who may feel more displaced in American university campuses than native-born students.

\section{Implications}

Beyond adding to the body of literature on attitudes toward mental health services of international students, the present study has important implications for student affairs personnel and mental health professionals who work with international 
students. Drawing on the findings, it is crucial for international students to be well informed and be made comfortable with seeking and using the mental health services available at their universities. As noted by Baer (2017), encouraging Chinese international students to reach out to faculty, staff, and counselors when facing challenges is already a high priority across many institutions of higher education in the United States. Mesidor and Sly (2016) found this approach works for international students in general, regardless of country of origin. However, little indication exists that these strategies include components that help international students become aware of or feel at ease about using such services.

One way to improve international students' awareness of these services could be accomplished through the development of system-wide protocols that remind international students about the importance of mental and emotional health. Such protocols could begin with incorporating mental health awareness checks into the process of international student orientation. This initial check can then be followed with periodic enlightenment campaigns and workshops to sensitize international students about coping with cultural adjustment stresses. Such follow-up programs can be organized in collaboration with student organizations, academic advisors, and host families where applicable. At each stage of these protocols, clarity should be provided to the students about what mental health indications are and what options they have when needing additional support. Most importantly, when these discussions about mental health are seen as normal and embraced system-wide, they can assist in countering the inhibitions that Chinese international students have toward seeking mental health services.

In addition, training international student officers and residence hall supervisors to be culturally sensitive in their interactions with international students can provide additional opportunities to incorporate emotional health checks into their conversation with international students. Chalungsooth and Schneller (2011) noted that culturally sensitive practices such as "greeting students in their native languages or having cross-cultural artifacts as office decorations..." allowed international students to be "...more at ease and more willing to disclose their concerns" (p. 182). Cheng et al. (2018) referred to such formative interactions as priming strategies and found these useful in helping to normalize professional mental health help-seeking behaviors. Culturally sensitive priming helps to prepare international students to engage in conversations about mental health with school officials when they have the need. At schools with significant numbers of Chinese or other international student populations, strategies in this category may be the most important bridge for helping students feel confident about seeking help for mental health concerns.

Likewise, awareness campaigns that specifically target male Chinese international students are crucial, given that they are less likely than their female counterparts to seek professional mental health services when unaware of the availability of such services. For this purpose, students can be educated on how to use self-assessment inventories and other noninvasive strategies to recognize early signs of emotional distress they may have. Students who are primed in this manner are more likely to take the next step of speaking with school officials or mental health counselors about their self-check results. 


\section{Limitations}

The findings in this study must be considered in light of several potential limitations to its external, construct, and internal validity. Data were gathered from a convenience sample of Chinese international students enrolled in two universities in the same state. Caution should be taken to avoid overgeneralizing these findings, as these may not directly apply to other populations of Chinese international students in the United States. Variations in the results may have been unaccounted for because the data collection was conducted using both in-person and electronic approaches. The demographic items were presented in both English and Mandarin on the survey administered in person but not on the electronic version of the survey. Also, no specific definitions for key terms such as mental health services and counseling were provided and may have affected responses to the survey. Some of the respondents may not have been familiar with these terms. Additionally, because a standard Chinese version of the ATSPPH-SF did not exist, the items were translated into Mandarin by one of the researchers who is fluent in both languages. This may also impose limitations on the construct and conclusion validity of the findings. Fang et al. (2011) noted that the construct of help-seeking as specified in the ATSPPH-SF fails to capture salient and culturally relevant dimensions of help-seeking for Chinese populations. If this is the case, a literal translation of the items into Mandarin may not fully compensate for this limitation.

Our findings do not suggest a causal relationship between students' demographic characteristics and their help-seeking attitudes. On the contrary, there may be an actual difference between the self-reported attitudes captured in this study and Chinese international students' actual mental health help-seeking behaviors. Despite these limitations, we are confident that the insights provided in this study can be of benefit to student affairs professionals as well as mental health practitioners seeking to improve the experience of the international students they serve.

\section{Suggestions for Future Studies}

International students from China and other countries choose to study in the United States for a variety of reasons. However, the thought of needing support beyond issues related to meeting their academic and financial commitments is not something many of them may have let cross their minds. Unfortunately, upon arrival, international students appear to face a wide range of stressors that can make their college experiences even more challenging than those of native-born students. Although many universities provide mental health and counseling support for their students, international students may be less informed about the availability of such facilities or be less willing to use these compared to other students. The current study was designed to explore this phenomenon among Chinese international students.

We recommend that future research could unpack how attitudes toward seeking mental health counseling may influence actual help-seeking behavior among Chinese international students. Such investigations may also examine the impact of other demographic factors such as English language skills, academic level (graduate versus undergraduate), prior academic performance, and social skills that were not 
considered in the present study. Additionally, a study of institutional level barriers that limit the ability of Chinese international students who would desire mental health support from seeking these would also provide useful insights. Ultimately, further research in this area should provide empirical evidence that helps student affairs practitioners and mental health professionals who work with college students to craft policies and programs that best serve their international student bodies.

\section{REFERENCES}

Akanwa, E. E. (2015). International students in stern developed countries: History, challenges, and prospects. Journal of International Students, 5(3), 271-284.

Alakaam, A. A., Castellanos, D. C., Bodzio, J., \& Harrison, L. (2015). The factors that influence dietary habits among international students in the United States. Journal of International Students, 5(2), 104-120.

Baer, J. (2017). Fall 2017 international student enrollment hot topics survey. Retrieved from https://www.iie.org/Research-and-Insights/OpenDoors/Data/Fall-International-Enrollments-Snapshot-Reports

Chalungsooth, P., \& Schneller, G. R. (2011). Development of translation materials to assess international students' mental health concerns. Journal of Multicultural Counseling \& Development, 39(3), 180-189.

Chang, H. (2008). Help-seeking for stressful events among Chinese college students in Taiwan: Roles of gender, prior history of counseling, and help-seeking attitudes. Journal of College Student Development, 49(1), 41-51.

Chen, H., Fang, X. Liu, C., Hu, W., Lan, J., \& Deng, L. (2014). Associations among the number of mental health problems, stigma, and seeking help from psychological services: A path analysis model among Chinese adolescents. Children \& Youth Services Review, 44, 356-362. doi: 10.1016/j.childyouth.2014.07.003

Chen, S. X., \& Mak, W. S. (2008). Seeking professional help: etiology beliefs about mental illness across cultures. Journal of Counseling Psychology, 55(4), 442450 .

Cheng, H., Wang, C., McDermott, R. C., Kridel, M., \& Rislin, J. L. (2018). Selfstigma, mental health literacy, and attitudes toward seeking psychological help. Journal of Counseling and Development, 96(1), 64-74. doi:10.1002/jcad.12178

Cohen, J. (1988). Statistical power analysis for the behavioral sciences. Lawrence Earlbaum Associates.

Elhai, J. D., Schweinle, W., \& Anderson, S. M. (2008). Reliability and validity of the attitudes toward seeking professional psychological help scale-short form. Psychiatry Research, 159(3), 320-329.

Fang, K., Pieterse, A. L., Friedlander, M., \& Cao, J. (2011). Assessing the psychometric properties of the attitudes toward seeking professional psychological help-short form in mainland China. International Journal for the Advancement of Counseling, 33, 309-321. doi:10.1007/s10447-011-9137-1

Fischer, E. H., \& Farina, A. (1995). Attitudes toward seeking professional psychological help: A shortened form and considerations for research. Journal of College Student Development, 36, 368-373. 
Fischer, E. H., \& Turner, J. L. (1970). Orientations to seeking professional help: development and research utility of an attitude scale. Journal of Consulting and Clinical Psychology, 35, 79-90.

Galligan, P. K. (2016). Male Chinese international students' utilization of and barriers to mental health resources [Doctoral thesis, University of Iowa]. Iowa Research

Online. https://ir.uiowa.edu/cgi/viewcontent.cgi?article $=6722 \&$ context $=$ etd

Heaslip, S. R. (2016). An investigation into the psychological help-seeking attitudes of persons with visual impairment [Master's thesis, University of British Columbia]. UBC Thesese and Dissertations. https://open.library.ubc.ca/cIRcle/collections/ubctheses/24/items/1.0228890

Huo, R. (2014). "Eating bitterness": mental health help-seeking and Chinese international students in the United States [Master's thesis, Smith College]. Smith Scholar Works. https://scholarworks.smith.edu/theses/786/

Hyun, J., Quinn, B., Madon, T., \& Lustig, S. (2007). Mental health need, awareness, and use of counselling services among international graduate students. Journal of American College Health, 56(2), 109-118.

Institute of International Education. (2017). Open Doors report. Retrieved June 29, 2018 from https://www.iie.org/Research-and-Insights/OpenDoors/Data/International-Students/Enrollment

Jibreel, Z. (2015). Cultural identity and the challenges international students encounter [Master's thesis, St. Cloud State University]. The Repository at St. Cloud

State. $\mathrm{http}: / /$ repository.stcloudstate.edu/cgi/viewcontent.cgi?article=1022\& context=en gl_etds

Joseph, J. (2010). Willingness to seek professional psychological help among Canadians of African descent: A culturally based help-seeking model [Doctoral dissertation, University of Windsor]. Scholarship at UWindsor. https://scholar.uwindsor.ca/cgi/viewcontent.cgi?article $=1486 \&$ context $=$ etd

Kataria, A. (2018, April 3). Trump's threats to restrict visas prompt Chinese students at Penn to adjust post grad plans. The Daily Pennsylvanian. http://www.thedp.com/article/2018/04/chinese-students-visa-trump-restrictionspenn-ivy-league-philadelphia

Kuo, B. C. H., Kwantes, C. T., Towson, S., \& Nanson, K. M. (2006). Social beliefs and determinants of attitudes toward seeking professional psychological help among ethnically diverse university students. Canadian Journal of Counselling, 40(4), 224-241.

Leong, F. T. L., \& Zachar, P. (1999). Gender and opinions about mental illness as predictors of attitudes toward seeking professional psychological help. British Journal of Guidance and Counselling, 27(1), 123-132.

Leong, P. (2015). Coming to America: Assessing the patterns of acculturation, friendship formation, and the academic experiences of international students at a U.S. college. Journal of International Students, 5(4), 459-474.

Li, J., Marbley, A. F., Bradley, L. J., \& Lan, W. (2016). Attitudes toward seeking professional counseling services among Chinese international students: 
Acculturation, ethnic identity, and English proficiency. Journal of Multicultural Counseling and Development, 44(1), 65-76.

Lu, S. H., Dear, B. F., Johnston, L., Wootton, B. M., \& Titov, N. (2014). An internet survey of emotional health, treatment seeking and barriers to accessing mental health treatment among Chinese-speaking international students in Australia. Counselling Psychology Quarterly, 27(1), 96-108. doi: $10.1080 / 09515070.2013 .824408$

Mak, W. W., \& Chen, S. X. (2006). Face concern: Its role on stress-distress relationships among Chinese Americans. Personality and Individual Differences, 41, 143-153. doi:10.1016/j.paid.2005.12.016

Melius, J., \& Cannonier, C. (2016). Exploring U.S. Hispanic parents' length of time in the United States: Influences on obesity outcomes among U.S. Hispanic children. Social Work in Health Care, 55(10), 826-842. doi:10.1080/00981389.2016.1223259

Merta, R. J., Ponterotto, J. G., \& Brown, R. D. (1992). Comparing the effectiveness of two directive styles in the academic counseling of foreign students. Journal of Counseling Psychology, 39(2), 214-218. doi:10.1037/0022-0167.39.2.214

Mesidor, J. K., \& Sly, K. F. (2016). Factors that contribute to the adjustment of international students. Journal of International Students, 6(1), 262-282.

Mohatt, N. V., Boeckmann, R., Winkel, N., Mohatt, D. F., \& Shore, J. (2017). Military mental health first aid: Development and preliminary efficacy of a community training for improving knowledge, attitudes, and helping behaviors. Military Medicine, 182(1), 1576-1583.

Mojaverian, T., Hashimoto, T., \& Kim, H. S. (2013). Cultural differences in professional help seeking: A comparison of Japan and the U. S. Frontiers in Psychology, 3, Article 615. doi:10.3389/fpsyg.2012.00615

Mortenson, S. T. (2006). Cultural differences and similarities in seeking social support as a response to academic failure: A comparison of American and Chinese college students. Communication Education, 55(2), 127-146. doi:10.1080/03634520600565811

Nam, S. K., Chu, H. J., Lee, M. K., Lee, J. H., Kim, N., \& Lee, S. M. (2010). A metaanalysis of gender difference in attitudes toward seeking professional psychological help. Journal of American College of Health, 59, 110-116.

Nasirudeen, A. A., Koh, J. W., Lau, A. C., Seng, L. L., \& Ling, H. A. (2014). Acculturative stress among Asian international students in Singapore. Journal of International Students, 4(4), 363-373.

Nina, A. (2009). International students' awareness and use of counseling services. McNair Scholars Research Journal, 5(1), Article 6.

Olivas, M., \& Li, C. S. (2006). Understanding stressors of international students in higher education: What college counselors and personnel need to know. Journal of Instructional Psychology, 33(3), 217-222.

O'Malley, B. (2018, October 5). Decline of international graduate enrolment quadruples. University World News. http://www.universityworldnews.com/article.php?story=20181005200448286

Pfohl, A. H. (2010). Factors influencing psychological help seeking attitudes and behaviors in counseling trainees [Doctoral dissertation, The Ohio State 
University].

OhioLINK.

http://rave.ohiolink.edu/etdc/view?acc_num=osu1293557571

Picco, L., Abdin, E., Chong, S. A., Pang, S., Shafie, S., Chua, B. Y., \& Subramaniam, M. (2016). Attitudes toward seeking professional psychological help: Factor structure and socio-demographic predictors. Frontiers in Psychology, 7, Article 547.

Qu, H. (2018). International student engagement in American higher education: Perspectives of international students toward services provided by the Office of International Services (Publication No. 10823934) [Doctoral dissertation, Saint Louis University]. ProQuest Dissertations \& Theses Global.

Saint Arnault, D. (2009). Cultural determinants of help seeking: A model for research and practice. Research and Theory for Nursing Practice: An International Journal, 23(4), 259-278.

Samovar, L. A., \& Porter, R. E. (1991). Intercultural communication: A reader (6th ed.). Wadsworth.

Sheu, H., \& Fukuyama, M. A. (2007). Counseling international students from East Asia. In H. Singaravelu \& M. Pope (Eds.), A handbook for counseling international students in the United States (pp. 173-193). American Counseling Association.

Sheu, H., \& Sedlacek, W. H. (2004). An exploratory study of help-seeking attitudes and coping strategies among college students by race and gender. Measurement and Evaluation in Counseling and Development, 37(3), 130-143.

Tang, T. T., Reilly, J., \& Dickson, J. M. (2012). Attitudes toward seeking professional psychological help among Chinese students at a UK university. Counselling \& Psychotherapy Research, 12(4), 287-293. doi:10.1080/14733145.2012.659747

Tedeschi, G. J., \& Willis, F. N. (1993). Attitudes toward counseling among Asian international and native Caucasian students. Journal of College Student Psychotherapy, 7(4), 43-54. doi:10.1300/J035v07n04_04

Tidwell, R., \& Hanassab, S. (2007). New challenges for professional counsellors: The higher education international student population. Counselling Psychology Quarterly, 20(4), 313-324.

Topkaya, N. (2014). Gender, self-stigma, and public stigma in predicting attitudes toward psychological help-seeking. Educational Sciences: Theory and Practice 14(2), 480-487.

Wang, H. (2013). Barriers to Chinese students seeking psychological help from professionals [Doctoral dissertation, University of Iowa]. https://ir.uiowa.edu/etd/2078

Wei, M., Heppner, P. P., Mallen, M. J., Ku, T., Liao, K. Y., \& Wu, T. (2007). Acculturative stress, perfectionism, years in the United States, and depression among Chinese international students. Journal of Counseling Psychology, 54(4), 385-394. doi:10.1037/0022-0167.54.4.385

Yakunina, E. S., \& Weigold, I. K. (2011). Asian international students' intentions to seek counseling: Integrating cognitive and cultural predictors. Asian American Journal of Psychology, 2(3), 219-224. doi:10.1037/a0024821 
Yan, K., \& Berliner, D. C. (2011). An examination of individual level factors in stress and coping processes: Perspectives of Chinese international students in the United States. Journal of College Student Development, 52(5), 523-542.

Yang, S., Salzman, M., \& Yang, C. H. (2015). Exploring the adjustment problems among international graduate students in Hawaii. Universal Journal of Educational Research, 3(3), 214-219.

Yoon, E., \& Jepsen, D. A. (2008). Expectations of and attitudes toward counseling: A comparison of Asian international and U.S. graduate students. International Journal for the Advancement of Counselling, 30(2), 116-127. doi:10.1007/s10447-008-9050-4

Yousaf, O., \& Popat, A. (2015). The bolstering effect of conceptual priming on psychological help-seeking attitudes in men. Journal of Mental Health, 24(6), 347-350. doi:10.3109/09638237.2014.998808

Zhang, N., \& Dixon, D. N. (2003). Acculturation and attitudes of Asian international students toward seeking psychological help. Journal of Multicultural Counseling and Development, 31(3), 205-222.

Zheng, K. (2016). Acculturative stress, attachment style and coping style of mainland Chinese international students in the United States [Doctoral dissertation, University of Cincinnati]. OhioLINK. http://rave.ohiolink.edu/etdc/view?acc_num=ucin1470044011

HUAN CHEN, EdS, is a graduate of the Cannon-Clary College of Education, Harding University, and is a doctoral candidate at the University of North Texas. Her research interests include play therapy, multicultural counseling, and counselor education. Email: hchen2@harding.edu

USENIME AKPANUDO, EdD, is an Associate Professor and Director of Research Initiatives in the Cannon-Clary College of Education, Harding University. His major research interests lie in the area of schools as organizations and professional identity. Email: uakpanud@harding.edu

ERIN HASLER, EdS, is a graduate of the Cannon-Clary College of Education, Harding University. Her major research interests lie in the area of child and adolescent behavior, counseling modalities, and the effects of social media. Email: ehasler@harding.edu 